\title{
Utilização e implicações dos antimicrobianos: a percepção de professores em formação
}

Jones Baroni Ferreira de Menezes

Eliane dos Santos Melo

Josilene Ferreira Oliveira

\section{Resumo}

Antibióticos são medicamentos com a finalidade de matar bactérias ou inibir seu crescimento. Representam claramente um dos maiores avanços na medicina, porém o uso indiscriminado e abusivo dessa classe de fármaco contribuiu para o grande problema de saúde pública, a resistência bacteriana. Nessa perspectiva, essa pesquisa foi proposta com o objetivo de compreender os saberes de licenciandos em Ciências Biológicas sobre uso e problemáticas dos medicamentos antimicrobianos. A pesquisa caracterizase como um estudo de caso descritivo e longitudinal, de abordagem quantitativa. Os dados foram coletados por meio da aplicação de um questionário a 33 discentes do nono semestre do curso de licenciatura em Ciências Biológicas da Faculdade de Educação de Crateús (FAEC), no qual se abordou o conhecimento a respeito dos antibióticos e seu uso, sobre resistência bacteriana, e os conhecimentos adquiridos no decorrer do curso. De acordo com os resultados, constatou-se que 67\% demostram um conhecimento adequado a respeito do conceito de antibióticos. Sobre a resistência bacteriana, todos os alunos compreendem sua conceituação e problemática. Ademais, a maioria dos discentes afirmaram fazer uso incorreto desses fármacos, utilizando de forma errônea ou por automedicação. Portanto, esse tema precisa ser mais abordado nas aulas levando ao conhecimento satisfatório, tanto para práticas de uso individual como para que a aprendizagem seja transmitida de forma eficiente para os estudantes.

Palavras-chave: Microbiologia. Ensino. Licenciatura. 


\title{
Use and implications of antimicrobials: the perception of teachers in training
}

\author{
Jones Baroni Ferreira de Menezes \\ Eliane dos Santos Melo \\ Josilene Ferreira Oliveira
}

\begin{abstract}
Antibiotics are medicines produced by microorganisms such as fungi or bacteria, used for the purpose of killing bacteria or inhibiting their growth. They clearly represent one of the greatest advances in medicine, but the indiscriminate and abusive use of this class of drug has contributed to the major public health problem, bacterial resistance. From this perspective, this research was proposed in order to understand the knowledge of undergraduates in Biological Sciences, in the final phase of the course conclusion, about antimicrobial drugs, their use and problems. The research is characterized as a descriptive and longitudinal case study with a quantitative approach. Data were collected by applying a questionnaire to 33 students of the ninth semester of the Biological Sciences degree course of the Faculty of Education of Crateús (FAEC), which addressed the knowledge about antibiotics and their use on resistance. bacterial, and the knowledge acquired during the course. According to the results, it was found that $67 \%$ of students showing adequate knowledge to respect to the concept of antibiotics, but the other students surveyed present difficulties in this conceptualization. About bacterial resistance, all students understand its conceptualization and problematic. In addition, most students reported misuse of these drugs by misuse or self-medication. Therefore, this theme needs to be more addressed in class leading to satisfactory knowledge, both for individual use practices and for learning to be transmitted efficiently to students.
\end{abstract}

Keywords: Microbiology. Teaching. Graduation. 


\section{Introdução}

O último século foi marcado por transformações no perfil de adoecimento e mortalidade no Brasil. Nele houve um aumento da prevalência das doenças crônicas não transmissíveis e uma diminuição das Doenças Infecciosas e Parasitárias (DIP). Contudo, as doenças infecciosas ainda representam desafios a serem superados pelo sistema de saúde, que é marcado por persistências ou reemergência de algumas endemias importantes, como a tuberculose e hanseníase e a dengue (SILVA-JÚNIOR, SILVA, CRUZ, 2018).

Parte das DIP são debeladas pelo uso de antibióticos, que são substâncias com a capacidade de impedir o crescimento de bactérias ou até mesma matá-las. Por esse motivo eles recebem duas principais classificações: bactericidas, quando usados para matar as bactérias, ou bacteriostáticos, quando apenas impedem o crescimento bacteriano. Portanto são fármacos utilizados para tratar de doenças infecciosas. (GUIMARÃES; MOMESSO; PUPO, 2010).

O descobrimento dos antimicrobianos foi um marco muito importante para a medicina, pois seu uso proporcionou uma significativa diminuição nos índices de morbidade e mortalidade humana causadas por infecções bacterianas, que até então consideradas fatais (MOTA et al., 2005). O primeiro antibiótico natural (denominado Penicilina) foi descoberto, acidentalmente, em 1928 pelo médico bacteriologista escocês Alexander Fleming. A partir de então, a indústria farmacêutica passou a realizar várias pesquisas que possibilitaram o desenvolvimento de novos fármacos dessa classe terapêutica (BITTENCOURT, 2014)

Desde as últimas décadas, o descobrimento de antibióticos eficazes contra doenças causadas por agentes infecciosos oportunizou um avanço considerável no campo da saúde, pois com a introdução de um tratamento adequado, ocorreu uma queda drástica na mortalidade humana ocasionada devido às infecções bacterianas que anteriormente eram consideradas potencialmente fatais. Esta classe de droga se destaca como a segunda mais utilizada, tanto é prescrita em grande escala como é usada por automedicação (MOTA et al., 2010).

Porém, o crescente e abusivo uso dos antimicrobianos vem potencializando o surgimento do fenômeno denominado resistência bacteriana, tornando-se um dos graves problemas de saúde pública (SILVEIRA et al., 2006). Em 2018, a Organização Mundial da Saúde (OMS) revelou altos níveis de resistência a uma série de infecções bacterianas graves em países de alta e baixa renda, com uma ocorrência generalizada de resistência aos antibióticos entre 500 mil pessoas com suspeita de infecção bacteriana em 22 países (OPAS, 2018).

A bactéria é considerada resistente a um antibacteriano, quando mesmo em contato com o fármaco, ela continua desenvolvendo todas suas funções e se multiplica originando novos agentes infecciosos, ou seja, o antibiótico não tem nenhum efeito sobre ela (CASTANHEIRA, 2013). Esse fenômeno vem evoluindo rapidamente devido a alguns fatores principais: prescrições incorretas do medicamento; uso abusivo ou inadequado dos mesmos; a globalização, onde viajantes infectados por cepas resistentes transmitem-nas a outras 
pessoas em outros países; e falta de sistemas globais de vigilância epidemiológica, que forneçam informações sobre como tomar decisões e elaborar políticas de terapia e regulação. Os principais problemas relacionados à resistência bacteriana são: tratamentos mais prolongados com custos mais elevados, devido à necessidade do uso de fármacos mais caros e às vezes mais tóxicos; aumento no tempo de internação; isolação do doente; aumento na possibilidade de contrair infecções hospitalares; maiores índice de morte associada a essas infecções (GURGEL; CARVALHO, 2008).

Assim, o problema da resistência bacteriana se torna cada vez mais preocupante, pois devido à existência de cepas resistentes a quase todas as classes de antibióticos, sempre há uma necessidade de fabricação de novos fármacos que possuam outros mecanismos de ação. Porém o desenvolvimento de novos agentes diminuiu bastante nos últimos anos (ROCHA et al., 2011).

A socialização dos conhecimentos técnicos para a sociedade é fundamental para a sensibilização quanto ao uso indiscriminado e incorreto dos antibióticos, de modo a minimizar a probabilidade do aparecimento de cepas resistentes. Portanto, o ensino da Microbiologia vem evoluindo bastante e se destacando como uma ciência multidisciplinar. Embora a Microbiologia seja uma disciplina de extrema importância para a formação acadêmica, ela ainda é tida como um desafio para muitos professores, principalmente para aqueles da maioria das escolas públicas, onde não existem laboratórios adequados para realização de aulas práticas da disciplina, o que prejudica o aprendizado do aluno que muitas vezes pode interpretar o ensino de maneira errada. Contudo ela não está mais apenas restrita a sala de aula ou laboratório, passou a ser abordada frequentemente como tema sobre questões de cidadania, incluindo meio ambiente, cotidiano e higiene (ORSO, 2014).

Diante do atual cenário de ensino nas escolas brasileiras, é importante notar a tamanha necessidade de se fazer uma conexão entre os temas abordados nas aulas de Ciências com o cotidiano dos alunos, pois isso facilita a compreensão dos conceitos e processos biológicos fazendo com que esse aprendizado retorne de maneira positiva para a sociedade (ANTUNES; PILLEGI; PAZDA, 2012). Destarte, tendo em vista que a formação em licenciatura capacita o estudante para atuar na área da educação como professor, é de extrema importância que este adquira conhecimento suficiente sobre os mais diversos aspectos no que diz respeito aos antibióticos, pois assim será capaz de transmitir esse conhecimento (MELLO, 2000).

Complementarmente, através da observância de um trabalhador em um ambiente de farmácia, no qual notou-se que muitas pessoas utilizam antibióticos incorretamente e de forma abusiva, gerou-se um questionamento de como o ensino a respeito dos antimicrobianos na universidade está sendo satisfatório tanto para conhecimento teórico como para a prática docente. Esse questionamento fez surgir a ideia da elaboração da presente pesquisa, objetivando compreender os saberes dos licenciandos de um curso de Ciências Biológicas, em 
fase final de conclusão do curso, sobre medicamentos antimicrobianos, seu uso, problemáticas e abordagem da temática durante o transcorrer da graduação.

\section{Percurso Metodológico}

A presente investigação caracteriza-se como um estudo de caso descritivo e longitudinal, de abordagem quantitativa. Ela ocorreu na Faculdade de Educação de Crateús, campi da Universidade Estadual do Ceará, no município de Crateús, localizado acerca de 350 km de Fortaleza, capital cearense. De acordo com o censo (2010) sua população é de 72.812 pessoas com uma densidade demográfica de 24,39 habitantes por quilômetros quadrados (IBGE, 2010).

Singularmente para esta pesquisa, os participantes foram 33 alunos do nono semestre do curso de Ciências Biológicas da FAEC. Optou-se por esse curso porque é onde a temática dessa pesquisa é mais abordada e a escolha do público pesquisado foi por ser discentes do último semestre de conclusão de curso, tendo em vista que brevemente atuarão como professores, sujeitos fundamentais na socialização de conhecimentos.

Os dados foram coletados por intermédio do uso de um questionário contendo 09 questões objetivas nas quais se abordava sobre o conhecimento prévio a respeito dos antibióticos, resistência bacteriana, o uso e aprendizagem durante o curso de Biologia. Também questionava se o curso de Ciências Biológicas proporcionou um aprendizado satisfatório, a fim de identificar se os participantes estão aptos a transmitir o conhecimento adquirido e fazer o uso racional desses insumos. A análise dos dados foi realizada através de estática descritiva, utilizando o Microsoft Office Excel 360, sendo apresentados por extenso ou em gráficos.

Neste trabalho foi respeitada a integridade de todas as informações prestadas, assumindo assim o compromisso com a ética e a cidadania de cada um, de acordo com os preceitos legais e administrativos como restabelece a Resolução 510/2016 (BRASIL, 2016).

\section{Resultados E Discussão}

Nessa pesquisa houve um total de 33 participantes que cursavam o nono semestre do curso de Ciências Biológicas. Sendo que 11 discentes responderam ao questionário enviado via correio eletrônico e 22 responderam ao questionário impresso, aplicado em sala de aula. Assim, iniciaremos na próxima subseção analisando os conhecimentos dos discentes sobre os antimicrobianos e resistência bacteriana.

\section{Conhecimentos sobre Antimicrobianos e Resistência Bacteriana}

Inicialmente solicitou-se aos discentes que assinalassem no questionário qual conceito sobre antibióticos de acordo com seu entendimento. Os resultados obtidos foram: 
67\% indivíduos assinalaram a opção que melhor caracteriza os antibióticos, onde conceituavaos como substâncias produzidas por micro-organismos como, fungos ou bactérias, existentes no mercado sobre forma de medicamentos capazes de matar ou inibir o crescimento de bactérias causadoras de infecções; 21\% optaram na afirmativa que versava serem compostos químicos sintéticos usados nos tratamentos ou prevenção de doenças infecciosas.

Assim, esses achados mostram que a maioria dos discentes, que estão se formando em Ciências Biológicas, possuem um conhecimento adequado a respeito do conceito de antimicrobianos.

Nesse sentido, Brito e Cordeiro (2012) caracterizam os antimicrobianos como um grupo de fármacos de relevante importância para a nossa sobrevivência, pois atuam na cura de diversas infecções bacterianas que são adquiridas tanto na comunidade como em leitos de hospitais. Na inexistência deles haveria diversas complicações em alguns casos, como, nascimentos de prematuros, transplantes, cirurgias, tratamentos de câncer etc. $\mathrm{E}$ isso influenciaria de forma negativa na nossa expectativa de vida.

Em contrapartida, $9 \%$ dos pesquisados assinalaram a afirmativa que conceituava os antibióticos como medicamentos capazes de combater inflamação, mostrando o desconhecimento sobre esse conceito.

Portanto, é nítido a incoerência sobre a afirmação acima, quando se observa que antibióticos são compostos utilizados para combater diversas infecções causadas por bactérias, seja matando-as ou inibindo seu crescimento. Sendo que, o conceito de infecção não deve ser confundido com o conceito de processo inflamatório. Nesse contexto é de grande valia ressaltar que essas substâncias não devem ser utilizadas para tratamento terapêuticos aos quais não estão destinadas, devido ao risco de surgimento de bactérias resistentes (RIBEIRO; PINTO; PEDROSA, 2009).

Ainda na mesma pergunta, constata-se que o1 participante (3\%) afirmou tratar-se de medicamentos utilizados para combater doenças causadas por vírus. Partindo dessa informação, embora represente um resultado de incidência mínima na pesquisa, é primordial destacar que há um equívoco na resposta, pois antibióticos são fármacos utilizados para tratamento de infecções causadas por bactérias, portanto a antibioticoterapia não é eficaz para tratar doenças causadas por vírus (MOTA et al., 2010).

A segunda interrogação tratava sobre os conhecimentos adquiridos ao longo do curso, indagando-os se estes serviram para mudar a posição quanto ao uso dos antibióticos. Em vista disso podemos observar que $88 \%$ responderam que sim e $12 \%$ responderam que não.

O uso indiscriminado de medicamentos antimicrobianos trata-se de um hábito bastante corriqueiro em ambientes familiares, inclusive entre estudantes. Essa ação geralmente é caracterizada pela influência de alguns fatores como, culturais, classe social e facilidade na aquisição do fármaco. Diante dessa situação, faz-se necessário que as instituições 
de ensino adotem planos educacionais que possam proporcionar a discursão, durante todo o processo de graduação, sobre o uso adequado desses insumos. Os estudantes precisam estar cientes a respeito de sua responsabilidade e conduta quanto consumidores, e principalmente sobre os perigos ocasionados pelo uso indevido e abusivo de medicamentos, bem como sua indicação a terceiros (BARBOSA et al., 2019).

Partindo desse pressuposto, o ensino de Biologia, por intermédio de suas diversas disciplinas, é de grande importância, pois leva os estudantes a aquisição de conhecimentos que, além de serem primordiais para melhorar sua qualidade de vida, promovem a capacidade para eles atuarem como transmissores daquilo que foi aprendido no decorrer do curso. Batista, Cunha e Cândido (2010, p. 4) confirmam sobre a influência do ensino de Biologia ao destacar que "[...] é importante dar ênfase ao conhecimento cognitivo dos estudantes, relacionando suas experiências, e os diferentes significados e valores que essa ciência pode ter para eles, para que a aprendizagem seja significativa."

Embora tenhamos obtido um resultado predominantemente positivo, vale destacar que $12 \%$ dos discentes afirmaram não ter mudado sua percepção quanto ao uso de antimicrobianos, mostrando que o ensino deve ser intensificado para promover a consciência sobre o uso correto de antibióticos.

Diante do fato citado acima, destaca-se a importância do ensino sobre antibióticos no curso de Ciências Biológicas, pois a universidade é o ambiente fundamental para proporcionar uma aprendizagem eficaz para os futuros professores, e que consequentemente também garante uma melhor qualidade de vida para estes e para a sociedade em geral (BÔAS, 2014).

Sobre a docência universitária em Biologia, Oda e Delizoicov (2012, p. 103) nos afirmam que "O estudo de temas relacionados à saúde, nas licenciaturas, busca dar aos futuros professores, conteúdos específicos necessários para a atuação do docente ao trabalhar o currículo do ensino médio (além do fundamental).”

Complementarmente, Krasilchik (2004, p. 197) nos traz que:

No estágio atual do ensino brasileiro, a formação biológica deve contribuir para que cada indivíduo seja capaz de compreender os processos e conceitos biológicos e a importância da ciência e da tecnologia na vida moderna, utilizando o que aprendeu ao tomar decisões de interesse individual e coletivo, tendo em vista a responsabilidade e respeito do papel do ser humano na biosfera.

Ainda na mesma questão, solicitou-se que os discentes listassem algumas disciplinas que foram fundamentais para a aprendizagem sobre antibióticos. Foram relatadas várias disciplinas do curso, conforme apresentado no gráfico 1. 
Gráfico 1: Disciplinas que forneceram subsídio para aquisição de conhecimentos sobre antibióticos.

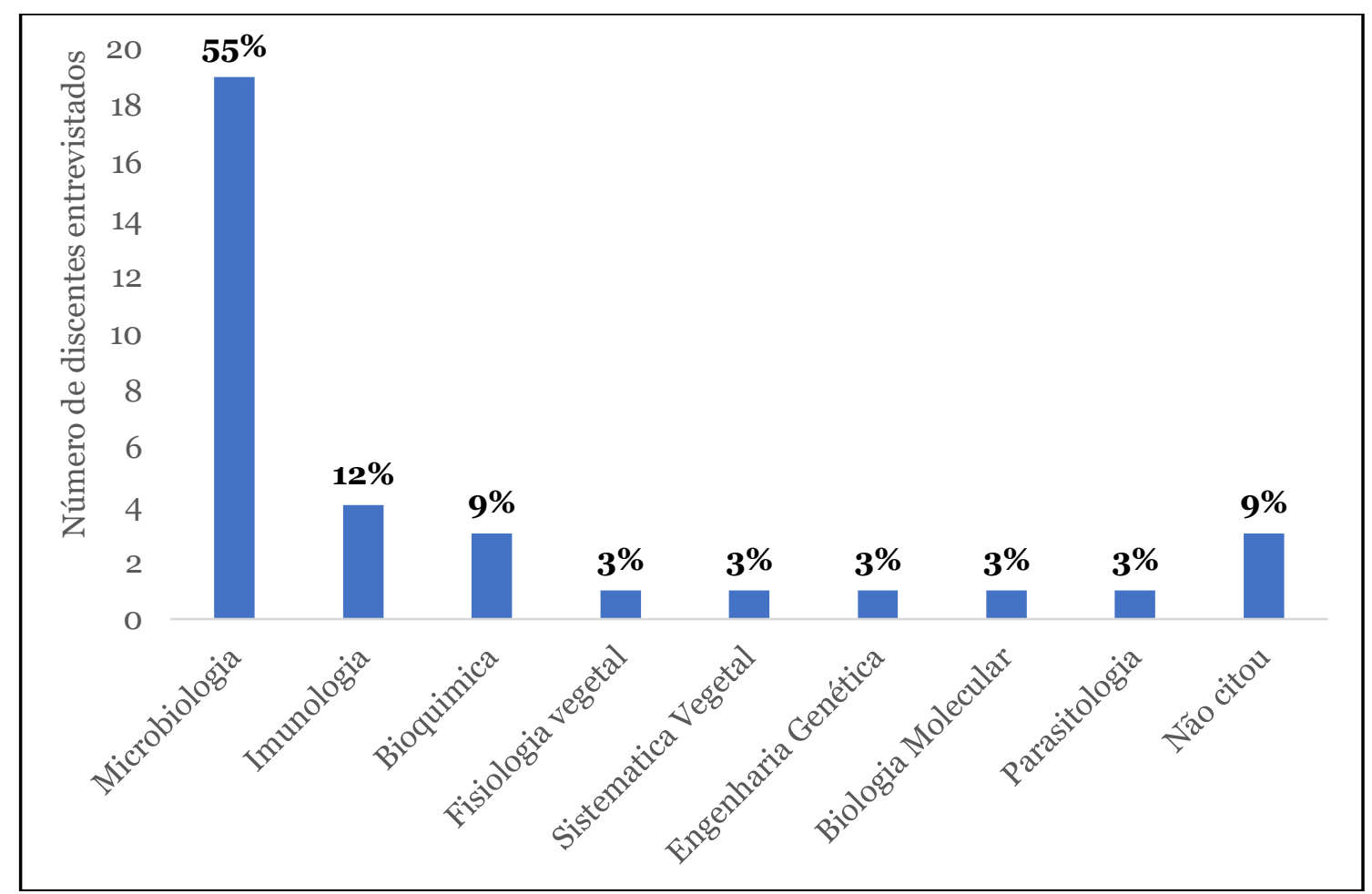

Fonte: Elaborado pelos autores.

Pelos resultados exposto no gráfico 1, observa-se que a disciplina de microbiologia tem sido a mais enfática e apresentado melhores resultados na promoção do ensino dos antibióticos, embora segundo Ferreira (2010, p. 7) destaque que ainda há um aprendizado deficiente porque "[...] a microbiologia é em grande parte negligenciada pelos professores, sendo tratada de forma meramente tradicional dentro do conteúdo referente aos seres vivos [...]."

A microbiologia (do grego: mikros, "pequenos", bios, "vida" e logos, “ciência”) é um ramo da Biologia que apresenta extrema importância, pois é por meio dela que adquirimos conhecimentos mais detalhados a respeito dos mais diversos microrganismos e como estes atuam em nossas vidas e na vida de outros seres do meio ambiente. Ao estudarmos sobre bactérias, vemos que algumas são causadoras de doenças infecciosas nos humanos, sendo que as infecções bacterianas necessitam de tratamentos específicos que só podem ser feitos com uso de antibióticos. Vale frisar que esses tratamentos só podem ser indicados por médicos, portanto deve-se evitar a automedicação (ORSO, 2014).

Nesse contexto, o ensino de microbiologia deve promover aprendizagem e assimilação de seus conteúdos com a maior clareza possível, oportunizando que os estudantes mudem seus hábitos e atitudes, tornando-os mais conscientes e capazes de enfrentar a vida no dia-a-dia, pois a microbiologia aborda temas que estão diretamente ligados à nossa saúde, higiene pessoal e aspectos fundamentais para o funcionamento do meio ambiente. Ao passo que ISSN 2526-2882

$$
\text { * } 177
$$


também os torna profissionais capacitados para explicar os fenômenos do universo dos microrganismos e demais temas assimilados nessa área (BARBOSA; BARBOSA, 2010).

Como mostra o gráfico 1, alguns participantes citaram as disciplinas de Imunologia, Biologia Molecular, Parasitologia, Bioquímica, Fisiologia Vegetal, Sistemática Vegetal e Engenharia Genética. Diante destas considerações observa-se a importância do ensino sobre os antibióticos nas mais variadas disciplinas, pois o ensino multidisciplinar proporciona maior subsídio para aquisição do conhecimento. Assim a área acadêmica pode atuar de forma a implementar a educação em saúde sobre os mais diversos temas, dentre eles, o uso dos antibióticos (DANDOLINI et al., 2012).

$\mathrm{Na}$ questão seguinte, indagamos sobre o conhecimento prévio a respeito da resistência bacteriana. Percebeu-se que $49 \%$ escolheram a opção onde versava que a resistência bacteriana é a capacidade que as bactérias têm de se multiplicar mesmo nas presenças de concentrações mais altas de antibióticos do que as que provêm de doses terapêuticas dadas aos humanos. Já $42 \%$ optaram pela alternativa que dizia ser um fenômeno biológico de adaptação natural das bactérias que se segue à introdução de agentes antimicrobianos na prática clínica. À medida que $9 \%$ assinalaram a alternativa que afirmava ser um problema que aumenta devido ao uso desmedido e irracional de antibióticos. Embora essas duas últimas opções não estarem incorretas, mas apresentam um conceito mais resumido.

Nos últimos anos, tem-se percebido uma grande preocupação com a resistência bacteriana, pois trata-se um problema de saúde pública mundial, onde os seus casos apresentam um crescimento acelerado, à medida que o desenvolvimento de novos fármacos não acompanha esse crescimento. Portanto é de grande importância o entendimento sobre essa temática para se evitar que suas consequências sejam cada vez mais desastrosa para a humanidade (ROCHA et al., 2011).

Nesse contexto, Fiol et al. (2010, p.68) complementa ao afirmar que:

O grande responsável pela disseminação dos genes de resistência e, por conseguinte de microrganismos resistentes, é sem dúvida o próprio homem; seja pela atitude inconsequente ou pela falta de informação, o uso irracional de antimicrobianos tem aumentado, a despeito de todas as publicações, campanhas e informações acerca do fato.

Sobre essa afirmação, observamos a necessidade potencializar o ensino a respeito da resistência bacteriana, pois ao aprender sobre essa temática podemos estar nos conscientizando do problema e, consequentemente, contribuiremos na diminuição dos altos índices de resistência bacteriana.

Diante do fato da problemática da resistência bacteriana, é importante que a formação biológica nas instituições de ensino seja eficaz, devendo contribuir para que os estudantes se tornem capazes de compreender os processos e conceitos biológicos. A conscientização sobre 
a questão da resistência bacteriana é uma opção fundamental para tentar minimizar ou até mesmo combater seu crescimento. À medida que se combate a resistência, os tratamentos das infecções tornam-se mais eficazes, melhorando a qualidade de vida. Nessa pespectiva, Korb, Teixeira e Rodrigues (2011) nos confirma que "[...] a melhor solução é a educação para promoção e a prevenção de doenças, para a promoção da qualidade de vida. [...]”. De um modo geral, tanta a educação como as informações sobre antibióticos, constituem soluções importantes para reverter as situações que contribuem diretamente com a prevalência da resistência bacteriana.

\section{O Uso de Antibióticos por acadêmicos do curso de Ciências Biológicas}

Os discentes foram indagamos sobre em quais situações eles faziam uso do antibiótico sem orientação de um profissional de saúde qualificado e os dados encontrados estão dispostos no gráfico 2.

Gráfico 2: Situações em que afirmam fazer uso de antibióticos sem orientação médica.

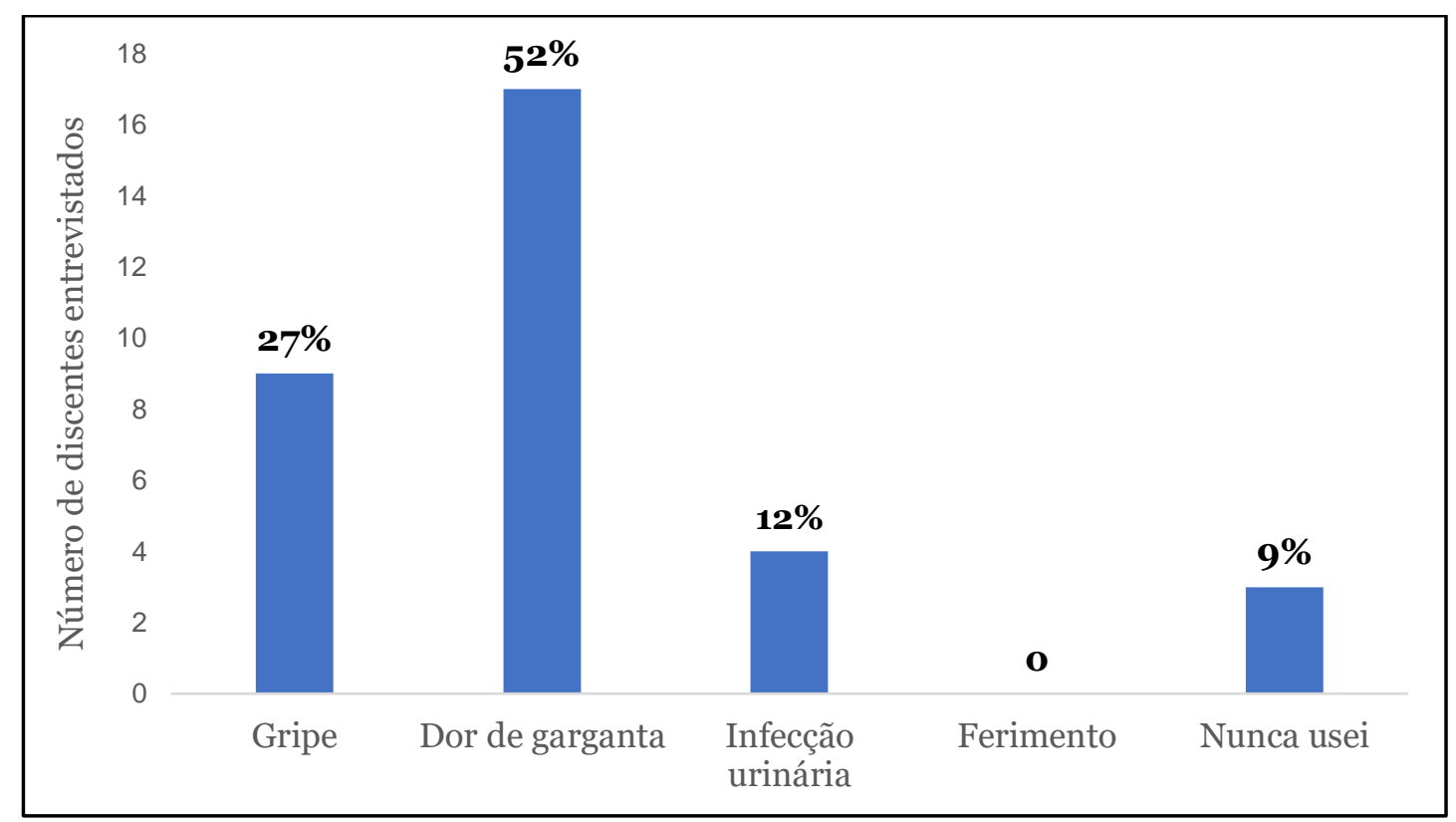

Fonte: Elaborado pelos autores.

Diante das respostas apresentadas, observa-se que os casos de dores de garganta (52\%) e gripe (27\%) foram os mais citados. Iuras et al. (2016) enfatizam que os principais motivos que levam a população se automedicarem são: precariedade no acesso ao serviço de saúde e ao atendimento médico; fiscalização ineficiente por parte dos órgãos governamentais responsáveis; e estímulo por meio de propaganda comercial etc. Por esse motivo, a automedicação vem crescendo significativamente tanto no Brasil como no mundo, sendo as regiões mais carentes as que mais realizam tal prática. Contudo, vale frisar que, mesmo com maior escolaridade, as classes sociais com maior condição financeira também costumam fazer ISSN 2526-2882

$$
* 179 *
$$


uso de medicamentos sem orientação médica, talvez porque acreditam que seus conhecimentos são suficientes para realizar essa prática.

A automedicação é uma prática em que a pessoa resolve tomar um fármaco por conta própria, sem a orientação de um profissional de saúde qualificado. O indivíduo toma a iniciativa de praticá-la baseando-se em orientações de terceiros ou em tratamentos realizados anteriormente, com objetivo de obter alívio imediato dos sintomas da infecção (MORAES; ARAÚJO; BRAGA, 2016).

Diante dos dados encontrados nessa questão, podemos observar que a automedicação com antibióticos ainda é uma prática muito comum entre universitários, embora eles tenham maior informação e mais oportunidade de educação na área. Corroborando com esses achados, Baggio e Formaggio (2009) apontam que a dor de garganta, gripe e outras causas estão inclusas entre as principais queixas que levam os estudantes à prática da automedicação. Em vista disso, é essencial ressaltar também sobre o risco de se automedicar, pois isso pode trazer diversos problemas de saúde, tanto individual como coletivo.

Contrariamente aos achados anteriores, onde apenas $3 \%$ dos discentes conceituaram os antibióticos como medicamentos utilizados para combater doenças virais, observa-se que 27\% afirmaram utilizá-los para tratamento gripal, uma doença causa por vírus. Portanto, observa-se que o ensino na universidade contribui mais para teoria do que para prática.

Seguindo esse pressuposto, Maier e Abegg (2007), em estudo semelhante à presente pesquisa, também observaram que os antibióticos são bastante solicitados e utilizados por paciente com a finalidade de tratar gripes e resfriados, condições estas de etiologia viral, onde o antibiótico não possui efeito. Portanto, isso mostra o desconhecimento do discente a respeito da aplicação e princípios de uso correto dos antimicrobianos.

Como já foi mostrado anteriormente, a automedicação é uma ação rotineira também presente no cotidiano dos estudantes. Diante disso, outra indagação posta foi para saber qual antimicrobiano os discentes costumavam tomar sem orientação de um médico e por quanto tempo durava o consumo.

Nesse contexto, demostrou-se que o fármaco mais citado foi a amoxicilina, onde ele é usado por $55 \%$ dos pesquisados, sendo que destes apenas $34 \%$ realizaram o tratamento por 7 dias. Já os demais costumavam usá-la por 2, 3 ou 5 dias. Os outros fármacos foram assinalados nas seguintes proporções: azitromicina (9\%), cefalexina (6\%) e ciprofloxacino (9\%). Porém (21\%) afirmam não usar nenhum destes.

Conforme já discutido, o uso indiscriminado e incorreto de antimicrobianos ocorre entre as mais variadas classes sociais. E nesse sentido, Conceição e Morais (2012) complementa ao afirmar que "[...] dois terços dos antimicrobianos são usados sem prescrição médica e de forma errada em muitos países”. E referente ao período de tratamento os dados coincidem com os achados de Nicolini et al. (2008, p. 690): 
“[...] 50\% dos consumidores compram o medicamento para um dia de tratamento 90\% compram-no para um período aproximado de três dias. Os antimicrobianos correspondem a aproximadamente $12 \%$ de todas as prescrições ambulatoriais, sugerindo um gasto aproximado de 15 bilhões de dólares ao ano com esses medicamentos."

Observa-se a necessidade de ações educativas sobre o tratamento com antimicrobianos, sobretudo para a alteração cultural da automedicação, pois estes fármacos apresentam dosagem, forma farmacêutica e período de tratamento específico para cada tipo de infecção (PASINATO, 2011).

Diante do exposto, salientamos que a automedicação deve ser evitada, principalmente no que se refere a tratamento com antibióticos. E quando houver necessidade de tratar alguma infecção, o médico ou profissional capacitado precisa ser consultado, pois somente estes possuem habilidades para atuar nessa área. É importante que o período do tratamento seja obedecido, evitando assim a proliferação da resistência bacteriana.

Ao serem questionados se já tinha interrompido tratamento com antibióticos prescritos pelo médico, observa-se que $46 \%$ dos discentes afirmaram nunca ter interrompido, $39 \%$ disseram ter interrompido, porém poucas vezes, $15 \%$ interromperam frequentemente.

Nesse contexto, salientamos que o uso incorreto de medicamento é uma ação que pode se tornar bastante prejudicial à saúde, principalmente no que se refere a antimicrobianos. E é o que acontece muitas vezes, onde a pessoa prolonga ou interrompe precocemente a prescrição e não obedece ao período estabelecido no receituário médico. Diante dessa perspectiva, destaca-se que a interrupção do tratamento com antibióticos é outro fator que contribui para que ocorra o processo de resistência bacteriana, um problema que causa limitação no tratamento de infecções devido ao aparecimento de cepas bacterianas resistentes aos antibióticos (MORAES; ARAÚJO; BRAGA, 2016).

Embora a resposta da maioria dos entrevistados seja positiva, é imprescindível alertar para que nos tornemos seres humanos cada vez mais capazes de realizar uma avaliação crítica e realista a respeitos dos nossos atos no que se refere ao uso de antimicrobianos, e assim, consequentemente, mais comprometidos com a Ciência.

\section{Influências do curso de Ciências Biológicas no aprendizado sobre antibióticos}

Os discentes também foram indagados sobre suas perspectivas a respeito do ensino sobre antibióticos no curso e 91\% assinalaram a opção que afirma dar uma base para orientar e oportunizar o uso adequado desse fármacos e 9\% optaram pela opção que indicava que o curso não traria muitas informações sobre o uso de antibióticos, pois os discentes consideravam que utilizavá-os corretamente.

Embora a questão aponte um resultado positivo, vale destacar que ainda existem algumas preocupações quanto ao ensino de biologia, pois há um grande desafio em que é 
necessário que a aprendizagem seja significativa para adquirir conhecimentos sobre temas fundamentais para se compreender os impactos de nossas ações na vida moderna. Tornandonos seres mais responsáveis no que se refere a tomada de atitudes, principalmente quando se fala em uso de antibióticos (KORB; TEIXEIRA; RODRIGUES, 2011).

Complementando Dandolini et al. (2012) aponta a educação como fonte essencial para conscientização sobre o uso racional de antibióticos, pois à medida que os estudantes aprendem sobre essa temática, estes repassam seu conhecimento para diferentes setores da comunidade e isso sobretudo em curso de formação de professores.

Na questão seguinte inquirimos se o curso de Biologia proporcionou conhecimento satisfatório sobre a automedicação com antibióticos, 70\% responderam sim, aprenderam que não devem realizar a automedicação com antibióticos, pois pode estar prejudicando a própria saúde e contribuindo para o desenvolvimento da resistência bacteriana. Enquanto 15\% consideram que o conhecimento foi satisfatório e que são capazes de ministrar a automedicação sem que haja algum desconforto ou prejudicialidade. E os demais 15\% responderam não, acreditam que não são capazes de realizar automedicação de forma adequada, mesmo com todo os conhecimentos adquiridos sobre antimicrobianos.

Observa-se a importância do ensino sobre automedicação com antibióticos nos cursos de Ciências Biológica, pois os discentes, quando orientados corretamente, tornam-se capazes de pôr em prática o que aprendeu em sala de aula e estarão aptos a transmitir o que aprendeu. A prática de ensinar aos acadêmicos sobre os riscos do consumo de antibióticos sem orientação médica é uma das maneiras de mostrar que a automedicação não é uma ação segura, podendo trazer diversos prejuízos para quem a prática (SOUZA; NETA, 2016).

Ao abordar sobre os conhecimentos adquiridos a respeito de automedicação com antibióticos, também estamos nos referindo a saúde, uma temática que deve ser discutida nas salas aula para uma melhor compreensão dos conceitos, como ressalta Silva (2018, p.18):

[...] a compreensão da Ciência é essencial para interpretar o mundo e melhorar a qualidade de vida. Assim, a escola necessita despertar o interesse pelos conceitos científicos fundamentais e verificar mais as ideias dos estudantes sobre o assunto, desenvolvendo atividades de compreensão e explicação dos fenômenos naturais, tornando assim, os estudantes capazes de aplicar o conhecimento científico em novas situações, permitindo que se atualizem quanto às inovações científicas e tecnológicas, emitindo opiniões sobre as mesmas.

Outra indagação foi se os discentes achavam importante a inserção de disciplinas da área da saúde na matriz curricular para uma melhor aprendizagem sobre resistência bacteriana. Nesse contexto, as respostas foram $67 \%$ sim e $33 \%$ não.

Korb, Teixeira e Rodrigues (2011), em pesquisa semelhante a esse trabalho, afirmam que a inserção de disciplinas relacionadas com a área da saúde é fundamental para a construção e consolidação do sistema democrático de ensino, pois proporciona que os sujeitos 
desenvolvam senso de suas responsabilidades pelas ações adotadas a respeito do uso de antimicrobianos.

Nessa mesma questão solicitou-se saber se haveria a necessidade de inserir alguma disciplina na matriz curricular que tratasse do tema e, em seguida, informasse qual. Assim, algumas disciplinsa foram pontuadas, como observado no gráfico 3.

Gráfico 3: Disciplinas que devem ser inseridas para melhorar a aprendizagem sobre resistência bacteriana

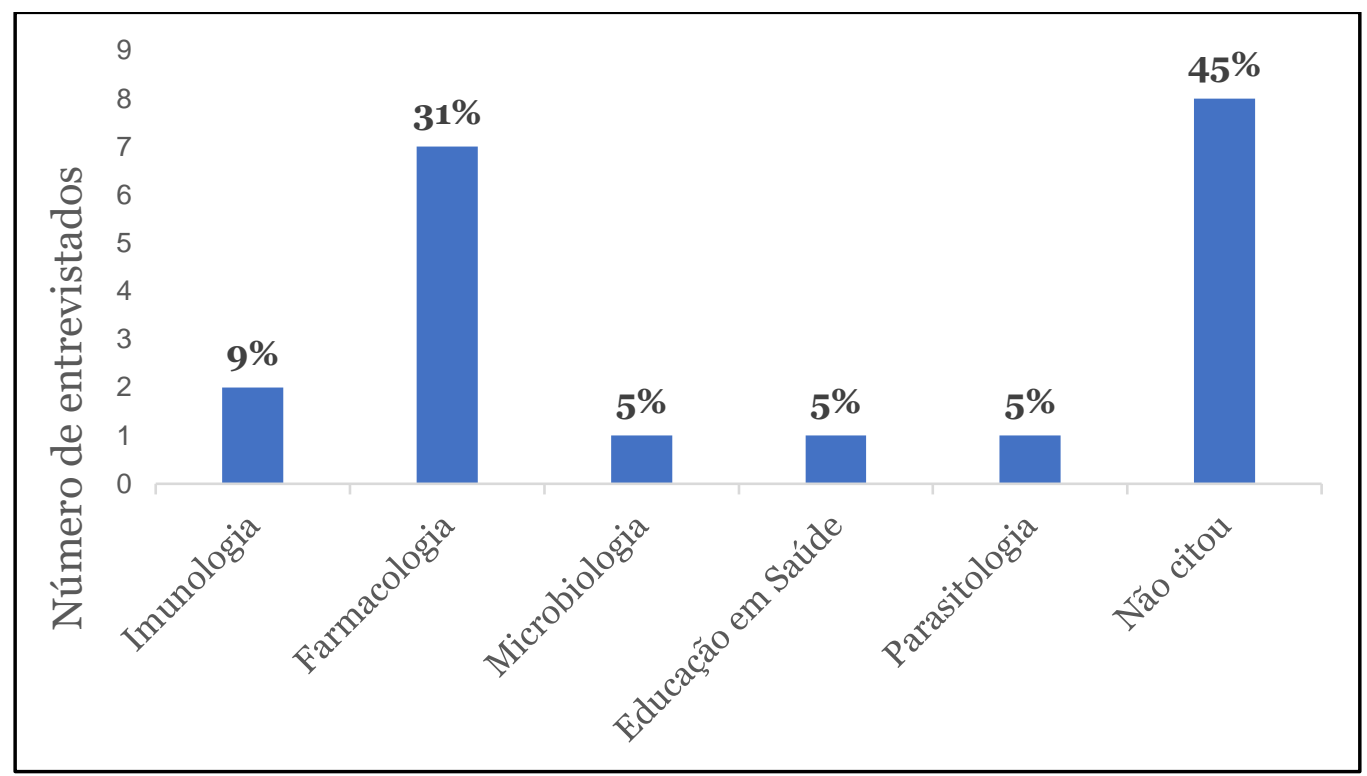

Fonte: Elaborado pelos autores.

No gráfico 3 estão listadas as disciplinas citadas pelos 22 (67\%) discentes que responderam sim, onde podemos observar que $45 \%$ destes não citou nenhuma disciplina. À medida que a disciplina de farmacologia foi citada por $31 \%$ dos que afirmaram sim. Embora seja uma disciplina do curso de Farmácia, observa-se o interesse dos licenciandos em aprofundar mais seus conhecimentos no que se refere ao tema saúde. Para Marini (2013), atualmente, o ensino superior em saúde vem sendo bastante criticado, pois os cursos deveriam cumprir com suas funções gerais especificas de seus programas, ou seja, o discente precisa aprender a desenvolver seu potencial intelectual, sua habilidade para as análises, raciocínio crítico, sua criatividade, capacidade de resolver problemas etc.

No que se refere a Educação em Saúde, que foi citada por $5 \%$ dos discentes, Sampaio (2014) afirma que a escola é ambiente que se constitui como um espaço importante para abordagem dessa temática, onde vários indivíduos da comunidade escolar atuam como uma rede de discursão sobre o tema saúde. As demais disciplinas citadas já estão presentes na matriz curricular do curso. 
Nesse intento, é que reforçamos a necessidade de uma Educação em Saúde nas escolas, de modo a contribuir na formação dos estudantes, pois estes passam a agir de forma mais inteligentes e com práticas que ajudam na preservação da saúde.

\section{Considerações Finais}

O ensino sobre antibióticos nas escolas é de fundamental importância, pois através dele os estudantes passam a ter mais conhecimento sobre os diversos aspectos do universo dos antibacterianos, entre eles o conceito, o uso correto, o fenômeno da resistência bacteriana e os riscos da administração sem orientação médica, à medida que os torna profissionais mais capacitados para atuaram na educação sobre essa temática.

No contexto a que se propõe esse trabalho, observa-se que os discentes fazem o uso de antibióticos sem orientação médica em vários casos de enfermidades infecciosas e na maioria das vezes sem obedecerem ao período correto de tratamento. E alguns ainda afirmam interromper o tratamento mesmo quando orientados por um profissional de saúde qualificado.

No tocante ao que se refere o conhecimento sobre a resistência bacteriana, é perceptível que os entrevistados têm consciência a respeito desse tema. Sendo que a aprendizagem é importante para se evitar seu crescimento, que vem tornando cada dia mais assustador, pondo em risco a nossa saúde. Porém, observa-se que os discentes possuem interesse em aprofundar seus conhecimentos na área da saúde, pois muitos concordam que é importante a inclusão de disciplinas da área da saúde na grade curricular do curso.

Analisando os conhecimentos adquiridos ao longo do curso, e se estes foram satisfatórios para que os discentes tornem-se capacitados para transmití-los, podemos perceber que a maioria tem ciência do conceito sobre antibióticos, porém uma parcela dos entrevistados apresentam dificuldades nessa conceituação. A maioria também afirma que o ensino proporcionou uma mudança de opinião quanto ao uso de antibióticos, contrariando os achados em outras indagações, onde verificamos que eles praticam a automedicação em diversas situações.

Por fim, constatamos a necessidade de aprimorar o ensino no que se refere aos antibióticos, tendo em vista que esse tema ainda é pouco abordado nas aulas e é de grande importância para a população em geral. Portanto, o ambiente escolar é o local mais apropriado para o aprendizado. O investimento na educação ainda é a opção mais coerente para enfrentarmos os problemas socioambientais. E os futuros professores devem estar mais capacitados para atuarem de forma positiva na transmissão do conhecimento.

\section{Referências}

ANTUNES, Carlos Henrique; PILEGGI, Marcos; PAZDA, Ana Karla. POR QUE A VISÃO CIENTÍFICA DA MICROBIOLOGIA NÃO TEM O MESMO FOCO NA PERCEPÇÃO 
DA MICROBIOLOGIA NO ENSINO MÉDIO? In: III SIMPÓSIO NACIONAL DE ENSINO DE CIÊNCIAS E TECNOLOGIAS, 3., 2012, Ponta Grossapr.SIMPÓSIO. Ponta Grossa-PR: III Simpósio Nacional de Ensino de Ciências e Tecnologias, 2012. p. 1 - 10.

ARAÚJO, Carlos Manuel Arantes. TRATAMENTO DA DIARRÉIA AGUDA. 2014. 62 f. Dissertação (Mestrado) - Curso de Ciências Farmacêuticas, Faculdade de Ciências da Saúde, Universidade Fernando Pessoa, Porto, 2014.

BAgGIO, Maria Aparecida; FORMAGGIO, Filomena Maria. AUTOMEDICAÇÃO: DESVELANDO O DESCUIDADO DE SI DOS PROFISSIONAIS DE ENFERMAGEM. Revista Enfermagem UERJ, Rio de Janeiro, v. 17, n. 2, p.224-228, jun. 2009. Disponível em: http://www.facenf.uerj.br/v17n2/v17n2a15pdf. Acesso em o4 de setembro de 2019.

BAPTISTA, Maria Galvão de Figueiredo Mendes. MECANISMOS DE RESISTÊNCIAS AOS ANTIBIÓTICOS. 2013. 42 f. Dissertação (Mestrado) - Curso de Ciências Farmacêuticas, Faculdade de Ciências e Tecnologias da Saúde, Universidade Lusófona de Humanidades e Tecnologias, Lisboa, 2013. Cap. 6.

BARBOSA, Flávio Henrique Ferreira; BARBOSA, Larissa Paula Jardim de Lima. Alternativas metodológicas em Microbiologia - viabilizando atividades práticas. Revista de Biologia e Ciências da Terra, Paraíba, v. 10, n. 2, p. 134-143, 2010.

BARBOSA, Lucas Lima et al. PREVALÊNCIA DA MEDICALIZAÇÃO NO ENSINO SUPERIOR. Revista Intercâmbio, Montes Claro, MG, v. 15, p.035-044, 2019. Anual. Disponível em: <http://www.intercambio.unimontes.br/index.php/intercambio/article/view/556>. Acesso em 12 de agosto de 2019.

BATISTA, Marcus Vinicius de Aragão; CUNHA, Marlécio Maknamara da silva; CÂNDIDO, Alexandre Luna. ANÁLISE DE TEMA VIROLOGIA EM LIVROS DIDÁTICOS DE BIOLOGIA DO ENSINO MÉDIO. Ensaio Pesquisa em Educação em Ciências, Minas Gerais, v. 12 n. 1 p.1-19, abr. 2010.

BITTENCOURT, Camila Coelho. O USO DOS ANTIMICROBIANOS: UMA PROPOSTA DE INTERVENÇÃO PARA ESF. 2014. 33F. Monografia (Especialização) - Curso de Especialização em Atenção Básica em Saúde da Família, Universidade Federal de Minas Gerais, Governador Valadares/ MG, 2014.

BÔAS, Rogério Custódio Vilas. MICROBIOLOGIA DO SOLO NO ENSINO MÉDIO: PROPOSTA DE FORMAÇÃO CONTINUADA DE PROFESSORES DE BIOLOGIA. 2014. 103 f. Tese (Doutorado) - Curso de Programa de Pósgraduação em Microbiologia Agrícola, Universidade Federal de Lavras, Lavras/MG, 2014 .

ISSN 2526-2882

$* 185 *$ 
BRASIL, Secretaria de Saúde de Minas Gerais (SES-MG). Vida saudável - alimentação e atividade física. 2016. Disponível em: http://www.saude.mg.gov.br/vida-saudavelalimentacao-e-atividade-fisica. Acesso em 18 de novembro de 2016.

, MINISTÉRIO DA SAÚDE. SECRETARIA DE VIGILÂNCIA EM SAÚDE. DEPARTAMENTO DE VIGILÂNCIA EPIDEMIOLÓGICA. Manual Integrado de Vigilância e Controle da Febre Tifóide. 1. ed. Brasília, DF: Editora MS, 2008. p. 1-92.

, MINISTÉRIO DA SAÚDE. SECRETARIA DE VIGILÂNCIA EM SAÚDE. DEPARTAMENTO DE VIGILÂNCIA EPIDEMIOLÓGICA. Manual Integrado de Vigilância Epidemiológica do Botulismo. 1. ed. Brasília: Editora MS, 2006. p. 1-88.

, Fundação Instituto Oswaldo Cruz. "É um milagre!". 2006. Disponível em: http://www.invivo.fiocruz.br/cgi/cgilua.exe/sys/start.htm?sid=7\&infoid=811.

Acesso em 07 de abril de 2016.

BRITO, Monique Araujo de; CORDEIRO, Benedito Carlos. Necessidade de novos antibióticos. Jornal Brasileiro de Patologia e Medicina Laboratorial. Rio de Janeiro, p. 247-249. 20 ago. 2012. Disponível em: <http://www.scielo.br/pdf/jbpml/v48n4/v48n4ao2>. Acesso em 10 agosto de 2019.

CASTANHEIRA, Bruno Alexandre Martins Guerreiro. MECANISMOS DE RESISTÊNCIA

A ANTIBIÓTICOS. 2013. 45 f. Dissertação (Mestrado) - Curso de Mestrado Integrado em Ciências Farmacêuticas, Faculdade Ciências e Tecnologias da Saúde, Universidade Lusófona de Humanidades e Tecnologias, Lisboa, 2013.

CONCEIÇÃO, Sebastião; MORAIS, Danyelle Cristine Marini de. AUTOMEDICAÇÃO COM ANTIBIÓTICOS EM ESTABELECIMENTO FARMACÊUTICO DO MUNICÍPIO DE MOGI MIRIM, SP, BRASIL. Foco: Caderno de Estudos e Pesquisas, São Paulo, v. 3, n. 3, p.23-34, 2012.

DANDOLINI, Bruna Werner et al. Uso Racional de Antibióticos: uma experiência para educação em saúde com escolares. Ciência \& Saúde Coletiva, [S.L], v. 17, n. 5, p.1323-1331, 2012.

FERREIRA, Andréa Fonseca. A importância da microbiologia na escola: uma abordagem no Ensino Médio. 2010. 56 f. TCC (Graduação) - Curso de Ciências Biológicas, Instituto de Biologia Roberto Alcantara Gomes, Universidade do Estado do Rio de Janeiro, Rio de Janeiro, 2010.

FIOL, Fernando de Sá del et al. Perfil de prescrições e uso de antibióticos em infecções comunitárias. Revista da Sociedade Brasileira de Medicina Tropical, [s.l.], v. 43, n. 1, p.68-72, fev. 2010.

ISSN 2526-2882 
GUIMARÃES, Denise Oliveira; MOMESSO, Luciano da Silva; PUPO, Monica Tallarico. Antibióticos: importância terapêutica e perspectivas para a descoberta e desenvolvimento de novos agentes. Química Nova, São Paulo, v. 33, n. 3, p.667-679, 24 fev. 2010.

GURGEL, Thaís C.; CARVALHO, Wânia S. A Assistência Farmacêutica e o Aumento da Resistência Bacteriana aos Antimicrobianos. Latin American Journal Of Pharmacy, [s.l], v. 27, n. 1, p.118-123, 2008.

IBGE- Instituto Brasileiro de Geografia e Estatística - cidade Crateús. 2010. Disponível em https://cidades.ibge.gov.br/brasil/ce/crateus/panorama. Acesso em 23 de julho de 2019.

IURAS, Anderson et al. Prevalência da automedicação entre estudantes da Universidade do Estado do Amazonas (Brasil). Revista Portuguesa de Estomatologia, Medicina Dentária e Cirurgia Maxilofacial, [s.l.], v. 57, n. 2, p.104-111, abr. 2016. Sociedade Portuguesa de Estomatologia e Medicina Dentaria (SPEMD). Disponível em: <https://www.sciencedirect.com/science/article/pii/S164628901600008X>.

Acesso em 04 setembro de 2019.

KORB, Arnildo; TEIXEIRA, Daiane Cristina; RODRIGUES, Renata Mendonça. Os conhecimentos em biologia na educação em saúde. Revista de Biologia e Ciências da Terra, $[\mathrm{s} .1], \quad$ v. $11, \quad$ n. $1, \quad$ p.1-9, 2011. Disponível em: $<$ https://www.redalyc.org/pdf/500/50021097011.pdf>. Acesso em 01 setembro de 2019.

KRASILCHIK, Myrian. Prática de ensino de biologia. 4. ed. São Paulo: Editora da Universidade de São Paulo, 2008. 201 p.

MAIER, Cristiane Roberta; ABEGG, Maxwel Adriano. AVALIAÇÃO DA UTILIZAÇÃO DE ANTIBIÓTICOS POR PROFISSIONAIS DE SAÚDE E PELA POPULAÇÃO NA CIDADE DE TOledo, PARANÁ, BRASIl. Arquivo de Ciência da Saúde da UNIPAR, Umuarama, v. 11, n. 1, p.19-25, 2007.

MELLO, Guiomar Namo de. Formação inicial de professores para a educação básica: uma (re)visão radical. São Paulo em Perspectiva, São Paulo, v. 14, n. 1, p.98-110, mar. 2000.

MORAES, Amanda Ludogerio; ARAÚJO, Nayara Gabriele Picanço; BRAGA, Tatiana de Lima. AUTOMEDICAÇÃO: REVISANDO A LITERATURA SOBRE A RESISTÊNCIA BACTERIANA AOS ANTIBIÓTICOS. Revista Eletrônica Estácio Saúde, Macapá, v. 5, n. 1, p.122-132, 2016.

MOTA, Leticia M. et al. USO RACIONAL DE ANTIMICROBIANOS. Medicina (Ribeirão Preto. Online), Ribeirão Preto, v. 43, n. 3, p.164-172, 30 set. 2010. Semestral. 
MOTA, Rinaldo Aparecido et al. Utilização indiscriminada de antimicrobianos e sua contribuição a multirresistência bacteriana. Brazilian Journal Of Veterinary Research And Animal Science, São Paulo, v. 42, n. 6, p.465-470, 01 jun. 2005. Trimestral.

NICOLINI, Paola et al. FATORES RELACIONADOS A PRESCRIÇÃO MÉDICA DE ANTIBIÓTICOS EM FARMÁCIA PÚBLICA DA REGIÃO OESTE DA CIDADE DE SÃO PAUlO. Ciência \& Saúde Coletiva, Rio de Janeiro, v. 13, p.689-696, abr. 2008. Mensal.

ODA, Welton; DELIZOICOV, Demétrio. Docência no Ensino Superior: as disciplinas Parasitologia e Microbiologia na formação de professores de Biologia. Revista Brasileira de Pesquisa em Educação em Ciências, [s.l], v. 11, n. 3, p.101-122, maio 2012.

OPAS. Novos dados revelam níveis elevados de resistência aos antibióticos em todo o mundo. Disponível em: https://www.paho.org/bra/index.php?option=com_content\&view=article\&id=5592 :novos-dados-revelam-niveis-elevados-de-resistencia-aos-antibioticos-em-todo-omundo\&Itemid $=812>.2018$.

ORSO, Priscilla. DIAGNÓSTICO DA APLICAÇÃo DE MODELAGEM MATEMÁTICA PARA ENTENDIMENTO DO CRESCIMENTO BACTERIANO. 2014. 39 f. Monografia (Especialização) - Curso de Especialização em Ensino de Ciências, Diretoria de Pesquisa e Pós-graduação, Universidade Tecnológica Federal do Paraná, Medianeira, 2014.

PASINATO, Roberta. Uso inadequado de antibióticos e suas consequências ao sus. 2011. 25 f. Monografia (Especialização) - Curso de Pós-graduação em Gestão de Organização Publica em Saúde- EaD, Centro de Educação Superior Norte do RS CESNORS, Universidade Federal de Santa Maria-UFSM, São Francisco de Paula/RS, 2011.

RIBEIRO, Maria; PINTO, Isabel; PEDROSA, Claudia. Comportamento da população do concelho de Vizela no consumo de antibióticos. Revista Portuguesa de Saúde Publica, Lisboa, v. 27, p.57-70, 2009. Trimestral. Disponível em: <http://www.scielo.mec.pt/scielo.php?pid=So87090252009000200006\&script=sc i_arttext\&tlng=en $>$. Acesso em: 10 agosto de 2019.

ROCHA, Diego Pessoa et al. Coordenação de metais a antibióticos como uma estratégia de combate à resistência bacteriana. Química Nova, São Paulo, v. 34, n. 1, p.111-118, 2011.

SAMPAIO, Aline Firminio. A TEMÁTICA EDUCAÇÃO EM SAÚDE NA FORMAÇÃO DE PROFESSORES DE CIÊNCIAS NATURAIS. 2014. 123 f. Dissertação (Mestrado) 
- Curso de Mestre em Ensino de Ciências, Instituto de Ciências Biológicas, Universidade de Brasília, Brasília, 2014.

SILVA, Michele Silveira da. UM ESTUDO SOBRE A FORMAÇÃO INICIAL DE PROFESSORES PARA A TEMÁtICA DA SAÚdE NA REGIÃo METROPOLITANA DE PORTO ALEGRE. 2018. 124 f. Dissertação (Mestrado) Curso de Programa de Pós-graduação em Educação em Ciências: Química da Vida e Saúde, Instituto de Ciências Básicas da Saúde, Universidade Federal do Rio Grande do Sul, Porto Alegre, 2018.

SILVA-JÚNIOR, VALDECIR BARBOSA; SILVA, MARIA TATIANE ALVES; CRUZ, DANILSON FERREIRA. Interface entre as Doenças Infecciosas e Parasitárias e a Estratégia Saúde da Família no Brasil. Revista Brasileira de Ciências da Saúde. Volume 24 Número 4 Páginas 325-332 2018.

SILVEIRA, Gustavo Pozza et al. Estratégias utilizadas no combate a resistência bacteriana. Química Nova, [s.1.], v. 29, n. 4, p.844-855, jul. 2006.

SOUZA, Deyverson Ricardo Pereira de; NETA, Maria Esméria. AUTOMEDICAÇÃO POR PROFISSIONAIS E ACADÊMICOS DA ÁREA DA SAÚDE: uma revisão de literatura. Revista da Universidade Vale do Rio Verde, Três Corações, v. 14, n. 2, p.965-974, 2016. Universidade Vale do Rio Verde (UninCor).

\section{Biografia Resumida}

Jones Baroni Ferreira de Menezes: Docente do curso de Ciências Biológicas da Faculdade de Educação de Crateús/Universidade Estadual do Ceará. Doutorando em Educação (PPGE/UECE). Mestre em Ciências Fisiológicas. Licenciado e Bacharel em Ciências Biológicas.

Lattes: http://lattes.cnpq.br/0220443059534591

Contato: jones.baroni@uece.br

Eliane dos Santos Melo: Graduada em Ciências Biológicas pela Faculdade de Educação de Crateús/Universidade Estadual do Ceará.

Lattes: https://orcid.org/oooo-00o1-7608-1298

Contatos: eliane.melo@aluno.uece.br

Josilene Ferreira Oliveira: Possui graduação em Ciências Biológicas pela Universidade Estadual do Ceará (2009). 
Atualmente é professora - quadro temporário da Escola de Ensino Médio Coelho Mascarenhas.

Lattes: http://lattes.cnpq.br/8810332535499116

Contatos: oliveirajosilene1@gmail.com 